Document downloaded from:

http://hdl.handle.net/10251/149941

This paper must be cited as:

Benajes, J.; García Martínez, A.; Monsalve-Serrano, J.; Boronat-Colomer, V. (2017). Particulates Size Distribution of Reactivity Controlled Compression Ignition (RCCI) on a Medium-Duty Engine Fueled with Diesel and Gasoline at Different Engine Speeds. SAE International Journal of Engines. 10(5):2382-2391. https://doi.org/10.4271/2017-24-0085

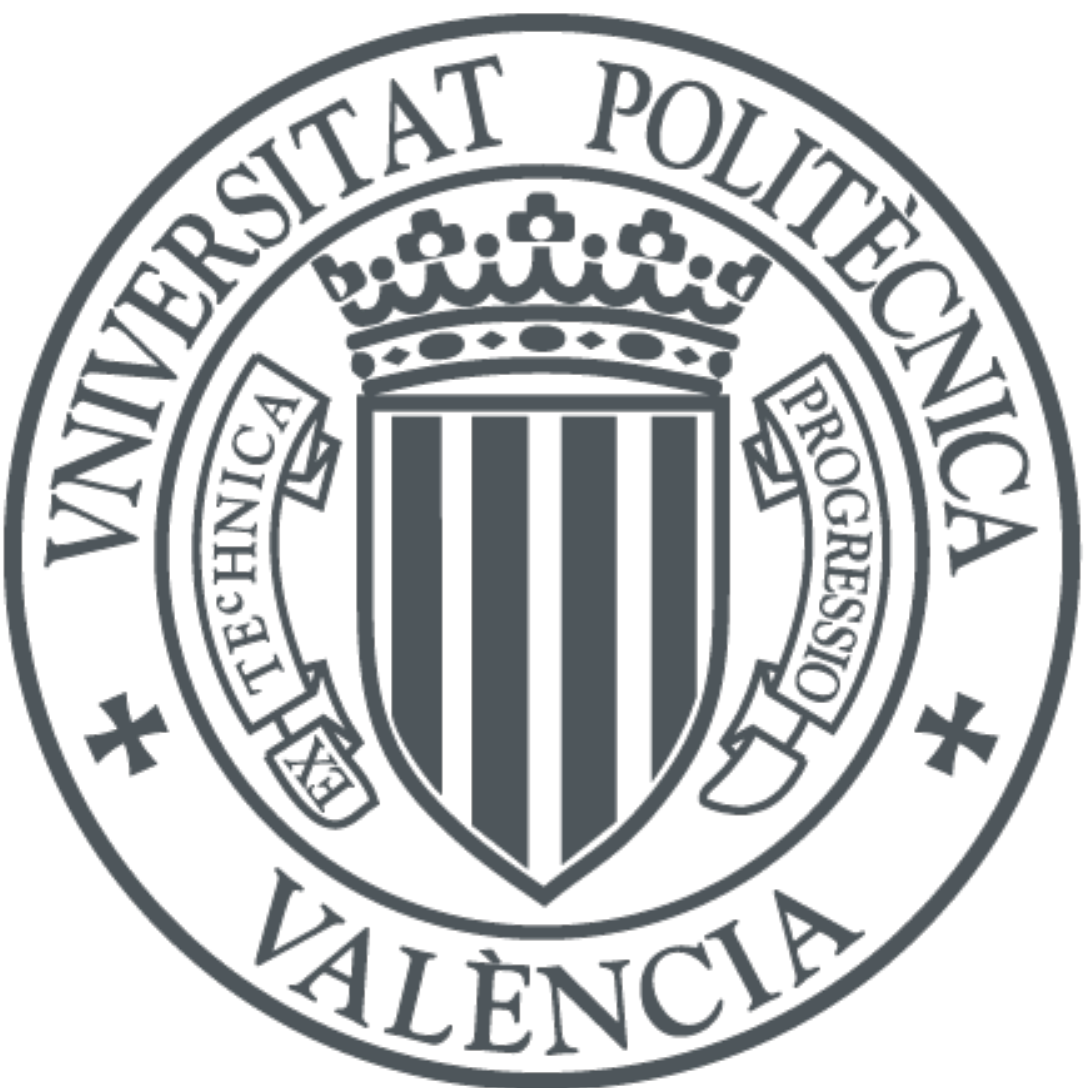

The final publication is available at

https://doi.org/10.4271/2017-24-0085

Copyright SAE International

Additional Information 


\title{
Particulates size distribution of Reactivity Controlled Compression Ignition (RCCI) on a medium-duty engine fueled with diesel and gasoline at different engine speeds
}

\author{
Jesus Benajes, Antonio Garcia, Javier Monsalve-Serrano, and Vicente Boronat
}

Universitat Politecnica de Valencia

\begin{abstract}
This work investigates the particulates size distribution of reactivity controlled compression ignition combustion, a dual-fuel concept which combines the port fuel injection of low-reactive/gasoline-like fuels with direct injection of highly reactive/diesel-like fuels. The particulates size distributions from 5-250 $\mathrm{nm}$ were measured using a scanning mobility particle sizer at six engine speeds, from 950 to $2200 \mathrm{rpm}$, and $25 \%$ engine load. The same procedure was followed for conventional diesel combustion. The study was performed in a single-cylinder engine derived from a stock medium-duty multicylinder diesel engine of 15.3:1 compression ratio. The combustion strategy proposed during the tests campaign was limited to accomplish both mechanical and emissions constraints. The results confirms that reactivity controlled compression ignition promotes ultra-low levels of nitrogen oxides and smoke emissions in the points tested. However, in spite of having similar or lower smoke emissions, the number of particles in some conditions is higher for the reactivity controlled compression ignition than for conventional diesel combustion. Nucleation mode dominates the particle formation for the reactivity controlled compression ignition mode, while accumulation mode dominates the particle formation for conventional diesel combustion. Thus, it is confirmed that the smoke measurement in filter smoke number units cannot be used to correlate the total particle mass for the reactivity controlled compression ignition mode, as typically done for conventional diesel combustion.
\end{abstract}

\section{Introduction}

Increasing environmental problems such as global warming and air pollution from vehicles have promoted more stringent emissions regulations in different countries around the world. Vehicle manufacturers have been worked hardly for updating the engines to face these new emissions regulations without penalizing the engine performance.

Compression ignition (CI) engines are extensively used in vehicle applications due to its high thermal efficiency. However, the nitrogen oxides (NOx) and smoke emissions still represent a challenge for the research community. To reduce NOx and smoke emissions under the limits imposed by the emissions regulations, $\mathrm{CI}$ engines require the addition of aftertreatment systems that increase the cost and complexity of the marketed vehicles. For the NOx reduction, the injection of urea fluid upwards the selective catalytic reduction (SCR) system is required to enhance the conversion reactions, which further increases the costs for the vehicle users.

During last decades, several strategies have been explored trying to maintain the benefits of the conventional diesel combustion (CDC) engines, but reducing the costs related to engine production, urea consumption and fuel consumption increase due to the passive diesel particulate filter (DPF) regeneration [1]. Among them, the low temperature combustion (LTC) strategies have been found able to provide a reduction of the smoke and NOx emissions and improve the efficiency simultaneously [2][3]. From these, it is worthy to highlight the homogeneous charge compression ignition (HCCI), partially premixed combustion (PPC), reactivity controlled compression ignition (RCCI) or dual-fuel combustion [4-6].

HCCI combustion technology was widely investigated by the research community. This strategy characterizes of using fully premixed lean air-fuel mixtures to achieve high thermal efficiency, low smoke and low NOx emissions simultaneously. However, HCCI combustion process is dominated by chemical kinetics, which difficult the concept in terms of ignition control, cold start and produces excessive levels of carbon monoxide (CO) and unburned hydrocarbons (HC) [7]. Hence, HCCI mode is limited to the partial load range [8]. To solve this shortcoming, Bessonette et al. [9] suggested that low loads would require the use of high reactivity fuels and low reactivity fuels should be used at high engine loads.

PCI strategy has been also deeply studied by the research community [10-11]. PCI emerges as a solution for the weaknesses of the HCCI mode by using low reactivity fuels. In this sense, the high ignitability of diesel fuel makes it suitable to be used for low load operation, requiring excessively high exhaust gas recirculation (EGR) rates as load increases [12]. Thus, the use of gasoline improves the heat release rate control and reduces the NOx and smoke emissions [1314]. Different octane number $(\mathrm{ON})$ gasolines were tested showing that the use of excessively high research octane number (RON) leads to unburning problems, being critical for gasolines with RON higher than 91. In this sense, gasoline presents a high resistance to ignite, which makes difficult to manage the combustion process at low load [15-16].

Park et al. [17] studied the effects of the fuel blends formed with diesel and gasolines. Inagaki et al. [18] proposed the dual-fuel PCI combustion concept feeding the engine with two fuels of different reactivity by means of separated injection systems. The different reactivity of the fuels was found to be a key factor for triggering the combustion phasing, also showing very promising results in terms of performance and emissions. Kokjohn et al. [19] continued this investigation and referred the combustion concept as reactivity controlled compression ignition (RCCI). This concept is the most promising LTC, achieving simultaneously low NOx and smoke emissions and high thermal efficiency under different fueling strategies [20][21] and hardware conditions [22][23]. RCCI presents excellent capabilities in order to overcome the challenges found with traditional LTC strategies. RCCI provides simultaneously low NOx and smoke emissions and high thermal efficiency. This strategy allows to reach high engine load while the combustion timing is under control [24]. 
From [25-27] is known that RCCI is capable enough to meet EU VI in terms of NOx at steady state operation points with low levels of smoke for heavy-duty engines. However, current emission regulations also limit the number of particles as well as the particle matter (PM). CI diesel engines usually form carbonaceous particles and their measurement is often mass-based. CI particle characterization studies have been widely carried out [28-29] in order to obtain the particle size distribution (PSD). These studies suggest that CI PSD present a bimodal shape, presenting both nucleation and accumulation modes, depending on the mobility diameter. For CDC operation mode, the cutoff diameter is typically located at $50 \mathrm{~nm}$. Therefore, nucleation mode particles would have mobility diameters lower than $50 \mathrm{~nm}$ and accumulation mode particles would contain particles with diameter larger than $50 \mathrm{~nm}$. For the traditional CI engines, Kittelson et al. [28] stated that nucleation mode particles might contain up to the $90 \%$ of the number of the particles but less than $20 \%$ of the PM mass emissions.

Storey et al. [30] carried out a speciation about the particles emitted under RCCI operation. The most important results indicate that the high boiling range of diesel hydrocarbons was surely responsible for the PM mass captured on the filter media. Additional studies showed that RCCI produces lower quantity of particles compared to other LTC strategies [31-32]. In this sense, Prikhodko et al. [33] carried out a PM study in a light-duty engine and stated that RCCI was highly dominated by nucleation mode particles and compared the smoke results in terms of filter smoke number (FSN) and PM filter mass measurements. The main conclusions were that RCCI PM is mainly organic carbon with almost no elemental carbon. Thus, implies that it is not possible to convert FSN in PM because of the low values of FSN measured at RCCI mode [34] due to the organic fraction.

The present study shows the results of the gaseous and PM emissions of a medium-duty engine operating under RCCI mode at $25 \%$ engine load. These results are also compared to the results of the same engine operated under CDC mode. The novelty of the study is to study the impact of varying the engine speed from $950 \mathrm{rpm}$ to 2200 $\mathrm{rpm}$ in a medium-duty engine. The study will focus on particles emission with a scanning mobility diameter between $5-250 \mathrm{~nm}$ by carrying out a PSD analysis.

\section{Experimental setup}

\section{Test cell and engine description}

RCCI operation mode has been implemented in a single-cylinder engine (SCE) adapted from a multi-cylinder engine (MCE). The MCE is a four-stroke, four in-line cylinders, medium-duty diesel engine that meets the EURO VI regulation. Main engine properties are shown in the table below.

Table 1. Main characteristics of the engine used.

\begin{tabular}{|l|l|}
\hline Style & 4 Stroke, DI diesel engine \\
\hline Manufacturer / model & VOLVO / D5K240 \\
\hline OEM ECU calibration & EURO VI \\
\hline Piston bowl geometry & Re-entrant \\
\hline Maximum power & $177 \mathrm{~kW} \mathrm{@} \mathrm{2200} \mathrm{rpm}$ \\
\hline Maximum brake torque & $900 \mathrm{Nm} @ 1200-1600 \mathrm{rpm}$ \\
\hline
\end{tabular}

Page 2 of 11

\begin{tabular}{|l|l|}
\hline Maximum in-cylinder pressure & $190 \mathrm{bar}$ \\
\hline Bore x Stroke & $110 \mathrm{~mm}$ x 135 mm \\
\hline Connecting rod length & $212.5 \mathrm{~mm}$ \\
\hline Crank length & $67.5 \mathrm{~mm}$ \\
\hline Total displaced volume & $5100 \mathrm{~cm} 3$ \\
\hline Number of cylinders & 4 \\
\hline Compression ratio & $15.3: 1$ \\
\hline
\end{tabular}

The adaptation to operate the engine as a SCE was carried out at CMT facilities and consists of removing the after-treatment elements as well as modifying the intake and exhaust manifolds to isolate the air management of one of the cylinders. Thus, one of the cylinders can be operated under RCCI regime while the other three cylinders run under CDC mode to balance the cylinder-to-cylinder pressure peaks. To allow this, an in-house control system was developed to manage the injection settings for the RCCI cylinder, while the ECU was in charge of the other three cylinders.

As can be observed in Figure 1, the test cell is fully instrumented and the engine is monitored in real time. The air management for the SCE has been redesigned and new elements such as an intake and exhaust air conditioners have been incorporated to the test bench. Intake air conditioner is formed by a screw compressor and an air dryer stage, controlling the humidity and a heater in order to adjust the temperature. Exhaust air management is in charge of the exhaust gases, controlling the back pressure, and the EGR supply. The low pressure (LP) EGR loop is formed by a screw compressor, a diesel particulate filter (DPF), a dryer to control the humidity and a heater to adequate the temperature. Additional equipment such as the instrumentation and the injection system is also needed for the SCE. As can be observed in Figure 1, CDC side engine has a cooler for the boosted air and the corresponding instrumentation required for the correct operating and safety of the engine.

Engine-raw gas emissions were sampled with a five gas Horiba MEXA-ONE-D1-EGR analyzer. Measurements were carried out by averaging $40 \mathrm{~s}$ after attaining steady state operation. An AVL 415 smoke meter was used for the smoke emissions measurements. Measurements were performed by averaging three samples of 1 liter volume each with paper-saving mode off. Results of these measurements are presented in filter smoke number (FSN) units. 


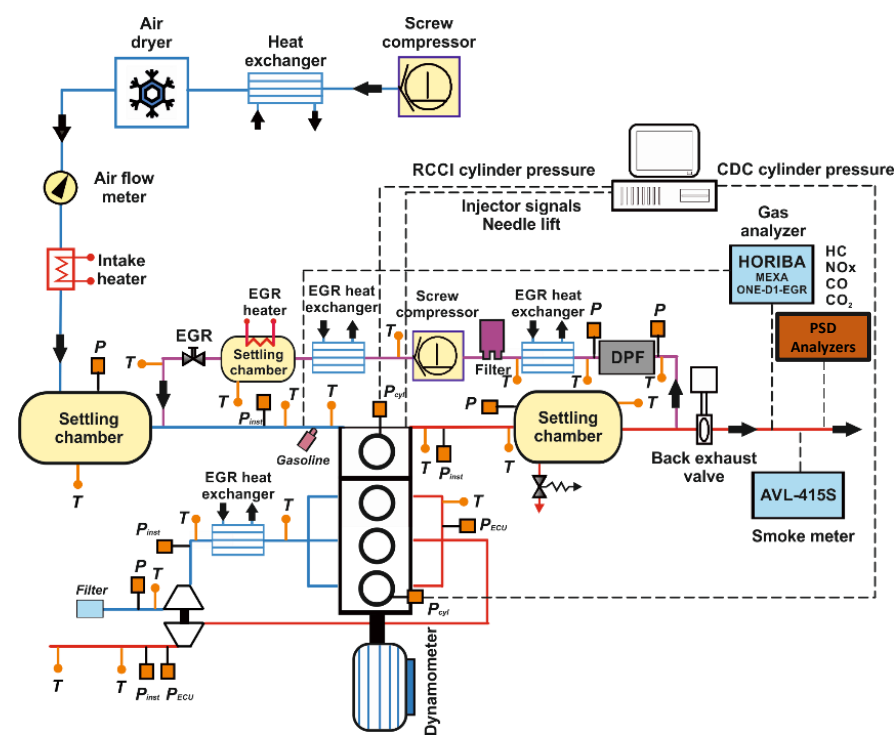

Figure 1. Test cell scheme.

In-cylinder pressure was measured with a Kistler $6125 \mathrm{C}$ pressure transducer coupled with a Kistler 5011B10 charge amplifier. A shaft encoder with 1800 pulses per revolution is used to obtain a crank angle degree $(\mathrm{CAD})$ with $0.2 \mathrm{CAD}$ resolution.

From the injection system standpoint, the stock diesel injector is used to supply diesel fuel into the combustion chamber and a port fuel injector (PFI) is installed at the intake manifold to supply the gasoline fuel. Main characteristics of the injectors are presented in table 2. Both injection systems are completed with two AVL 733S in order to measure the fuel mass flow. Both injectors are driven using a National Instruments (NI) DRIVVEN control system. The in-house developed control allows to operate the engine between different engine points automatically, being able to carry out transitions between engine speeds for instance.

Table 2. Main properties of the diesel and gasoline injector.

\begin{tabular}{|l|l|}
\hline \multicolumn{2}{|c|}{ Diesel injector } \\
\hline Actuation Type & Solenoid \\
\hline Steady flow rate @ 100 bar $\left[\mathrm{cm}^{3} / \mathrm{min}\right]$ & 1300 \\
\hline Number of Holes & 7 \\
\hline Hole diameter $[\mu \mathrm{m}]$ & 177 \\
\hline Included Spray Angle $\left[^{\circ}\right]$ & 150 \\
\hline Maximum injection pressure (bar) & 1200 \\
\hline \multicolumn{2}{|c}{ Gasoline injector } \\
\hline Injector Driver & Saturated \\
\hline Steady flow rate @ 3 bar [cm $3 / \mathrm{min}]$ & 980 \\
\hline Included Spray Angle $\left[{ }^{\circ}\right]$ & 30 \\
\hline Injection Pressure $[\mathrm{bar}]$ & 5.5 \\
\hline Injection Strategy & Single \\
\hline Start of Injection Timing & 340 CAD ATDC \\
\hline
\end{tabular}

The low reactivity fuel selected has been gasoline with 95 RON (EN 228) and the high reactivity fuel used is the regular diesel (EN 590). The main characteristics are presented in table 3 .

Page 3 of 11
Table 3. Physical and chemical properties of the fuels used.

\begin{tabular}{|l|l|l|}
\hline & Diesel EN590 & Gasoline \\
\hline Density $\left[\mathrm{kg} / \mathrm{m}^{3}\right]\left(\mathrm{T}=15^{\circ} \mathrm{C}\right)$ & 820 & 720 \\
\hline Viscosity $\left[\mathrm{mm}^{2} / \mathrm{s}\right]\left(\mathrm{T}=40{ }^{\circ} \mathrm{C}\right)$ & 2.8 & - \\
\hline RON [-] & - & 95.0 \\
\hline MON [-] & - & 85.0 \\
\hline Cetane number [-] & $>51$ & - \\
\hline Lower heating value $[\mathrm{MJ} / \mathrm{kg}]$ & 42.97 & 42.4 \\
\hline
\end{tabular}

As shown in Figure 2, particle size distribution measurements has been carried out by using a diluter, a scanning mobility particle size (SMPS) and a condensation particle counter (CPC). The measurement equipment is located after the exhaust backpressure, which is located immediately before the exhaust settling chamber. The diluter chosen is a TSI Rotating Disk thermodiluter, which dilutes the sample by means of a rotating disk method. Every measurement unit is provided by two disks in order to obtain different number of cavities. The next step consist of a raw portion of the exhaust flow captured by the cavities driven into the mixer with particle-free air. This step ensures good stability and accuracy. Due to the volatiles could cause condensates, air sample must be heated and, hence the equipment will not confuse nanodroplets with particles. This step adapt the inlet concentration of the particles, which is required by the SMPS equipment.

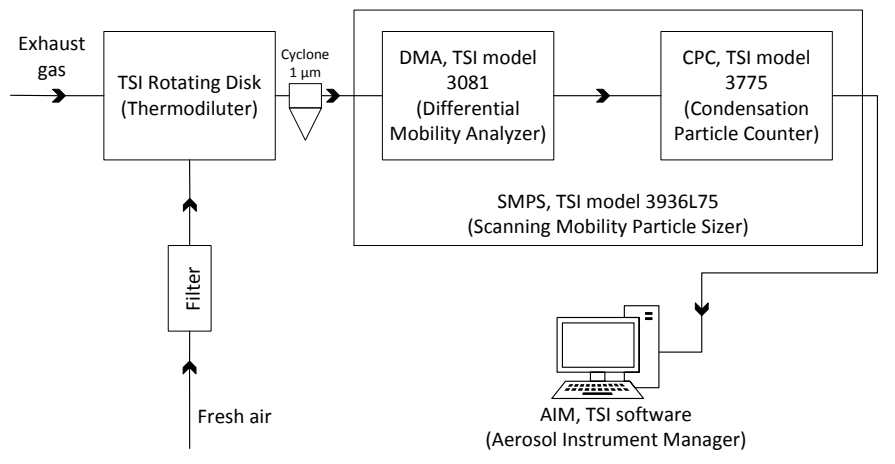

Figure 2. PSD analyzers scheme.

DMA measurement principle consists of the ability of a particle to cross an electric field is directly related to the size of the particle. Following to this step, a (CPC) counts particles between 5-250 nm. Finally, an Aerosol Instrument Manager (AIM, TSI) software is in charge of the data acquisition and PSD processing.

\section{Results and discussion}

Results have been divided in two subsections. The first one analyzes the RCCI combustion development comparing it versus the CDC operation. The second subsection is completely focused on the particle matter analysis. 


\section{RCCI combustion analysis}

Figure 3 presents the steps followed to reach RCCI operating conditions. The first step proposed consists of achieving the desired engine load, while the mechanical constraints in terms of maximum pressure rise rate (PRR) and the maximum in-cylinder pressure are below 15 bar/CAD and 190 bar, respectively. The second step is required to reduce smoke emissions below 0.1 FSN and NOx emissions below the limit imposed by the EURO VI regulation, 0.4 $\mathrm{g} / \mathrm{kWh}$. The third step consists of a fine tuning of the injection timing and gasoline fraction (GF) in order to reduce the fuel consumption to similar or lower values than with CDC reference. A detailed explanation of this methodology can be found at [35].

\begin{tabular}{c}
$\begin{array}{c}\text { Target } 1 \rightarrow \text { Engine load } \\
\text { Mechanical constraints } \\
\left(P R R<15 \text { bar/CAD; } P_{\max }<190 \text { bar }\right)\end{array}$ \\
\hline Target $\mathbf{2} \rightarrow$ EURO VI NOx limits and low smoke \\
emissions \\
$(N O x<0.4$ g/kWh; Smoke $<0.1$ FSN $)$
\end{tabular}

Figure 3. Strategy followed to operate under RCCI mode.

Tables 4 and 5 summarize the indicated specific emissions of NOx, $\mathrm{CO}$, smoke and $\mathrm{HC}$ for RCCI and CDC modes at different engine speeds. Moreover, the indicated mean effective pressure (IMEP) and EGR rate are depicted in both tables.

Table 4. Engine-out emissions and EGR rate for RCCI mode.

\begin{tabular}{|c|c|c|c|c|c|c|}
\hline Speed & IMEP & EGR & ISNOx & ISCO & ISHC & Smoke \\
\hline rpm & bar & $\%$ & $\mathrm{~g} / \mathrm{kWh}$ & $\mathrm{g} / \mathrm{kWh}$ & $\mathrm{g} / \mathrm{kWh}$ & FSN \\
\hline 950 & 4.9 & \multirow{6}{*}{20} & 0.069 & 54.4 & 9.8 & 0 \\
\hline 1200 & 6.3 & & 0.051 & 20.7 & 7.2 & 0.08 \\
\hline 1500 & 7.3 & & 0.157 & 9.7 & 7.3 & 0.12 \\
\hline 1800 & 7.4 & & 0.203 & 12.0 & 7.6 & 0.11 \\
\hline 2000 & 7.1 & & 0.203 & 16.9 & 8.2 & 0.03 \\
\hline 2200 & 6.8 & & 0.114 & 35.7 & 9.2 & 0.02 \\
\hline
\end{tabular}

The strategy followed to perform the CDC operating points is based on replicating the stock combustion settings. Small differences are observed at the intake air conditions due to the low pressure (LP) EGR loop respect from the high pressure EGR loop.
Table 5. Engine-out emissions and EGR rate for CDC mode.

\begin{tabular}{|l|l|l|l|l|l|l|}
\hline Speed & IMEP & EGR & ISNOx & ISCO & ISHC & Smoke \\
\hline rpm & bar & $\%$ & $\mathrm{~g} / \mathrm{kWh}$ & $\mathrm{g} / \mathrm{kWh}$ & $\mathrm{g} / \mathrm{kWh}$ & $\mathrm{FSN}$ \\
\hline 950 & 4.5 & 20.0 & 3.5 & 0.8 & 0.3 & 0.07 \\
\hline 1200 & 6.3 & 18.2 & 3.8 & 0.6 & 0.2 & 0.1 \\
\hline 1500 & 6.9 & 24.1 & 3.0 & 0.4 & 0.2 & 0.1 \\
\hline 1800 & 7.0 & 23.8 & 3.1 & 0.6 & 0.2 & 0.14 \\
\hline 2000 & 7.0 & 25.2 & 2.6 & 0.7 & 0.2 & 0.17 \\
\hline 2200 & 7.1 & 13.3 & 3.4 & 0.7 & 0.2 & 0.2 \\
\hline
\end{tabular}

To facilitate the comparison between results from both combustion modes and foresee the emissions trends with respect to the engine speed, the emissions measurements of tables 4 and 5 have been represented in Figure 4.
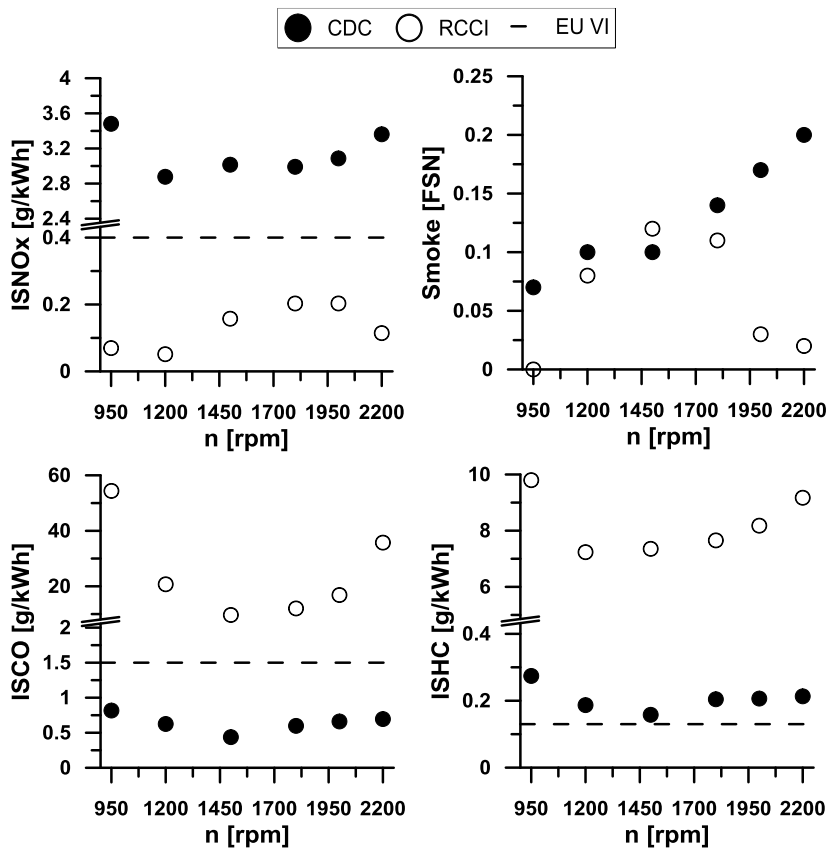

Figure 4. Engine-out emissions for RCCI and CDC at different engine speeds.

Figure 5 and 6 show instantaneous profiles for the most important parameters related to the combustion development. In particular, the in-cylinder pressure, rate of heat release (RoHR) and bulk gas temperature are depicted for both combustion strategies at all the engine speeds.

From the smoke emissions standpoint, both concepts present low values. As it can be observed in Figure 4, RCCI presents a bigger difference from $1800 \mathrm{rpm}$ to $2200 \mathrm{rpm}$. As depicted in Figure 3, the smoke target is set at $0.1 \mathrm{FSN}$ for the RCCI concept. However, Figure 4 shows that two points (1500 rpm and $1800 \mathrm{rpm})$ exceed the maximum value despite of having a mixing time of around $4 \mathrm{~ms}$. As the premixing conditions are not explaining this values of smoke obtained, the reason might be related with the nature of the particles. 
Thus, this particular case would be explained in detail in the PSD section.

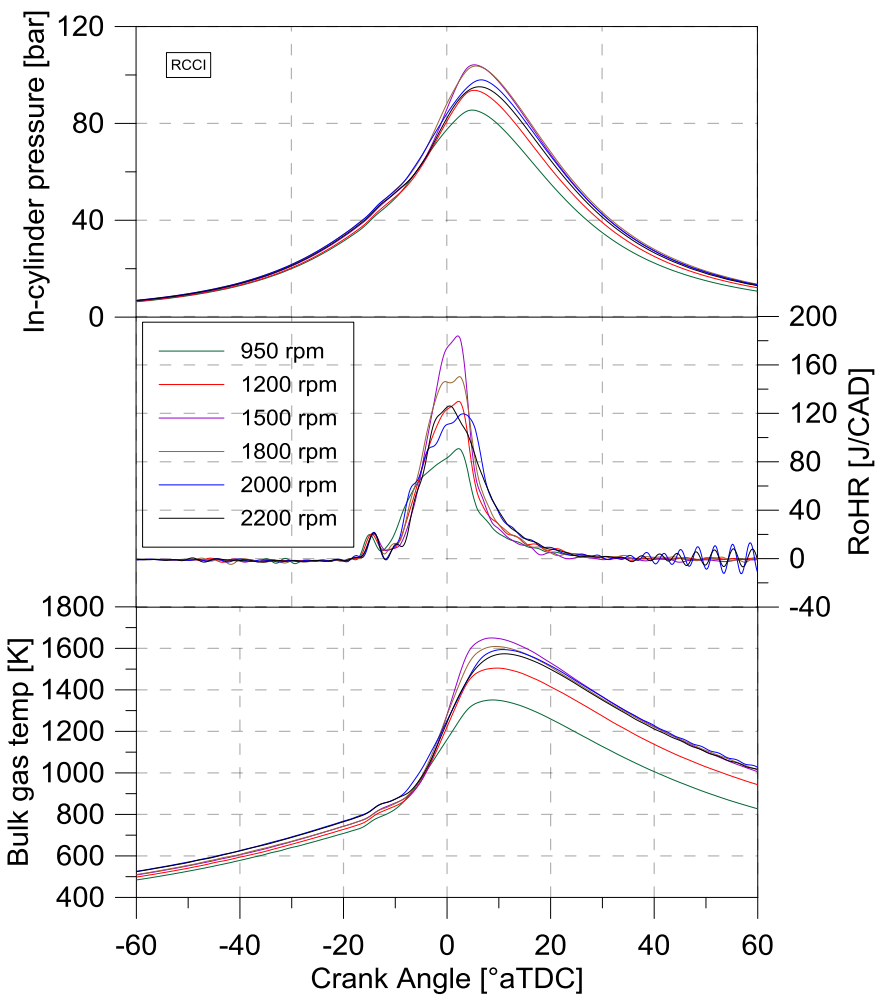

Figure 5. In-cylinder pressure, rate of heat release and bulk gas temperature for RCCI.

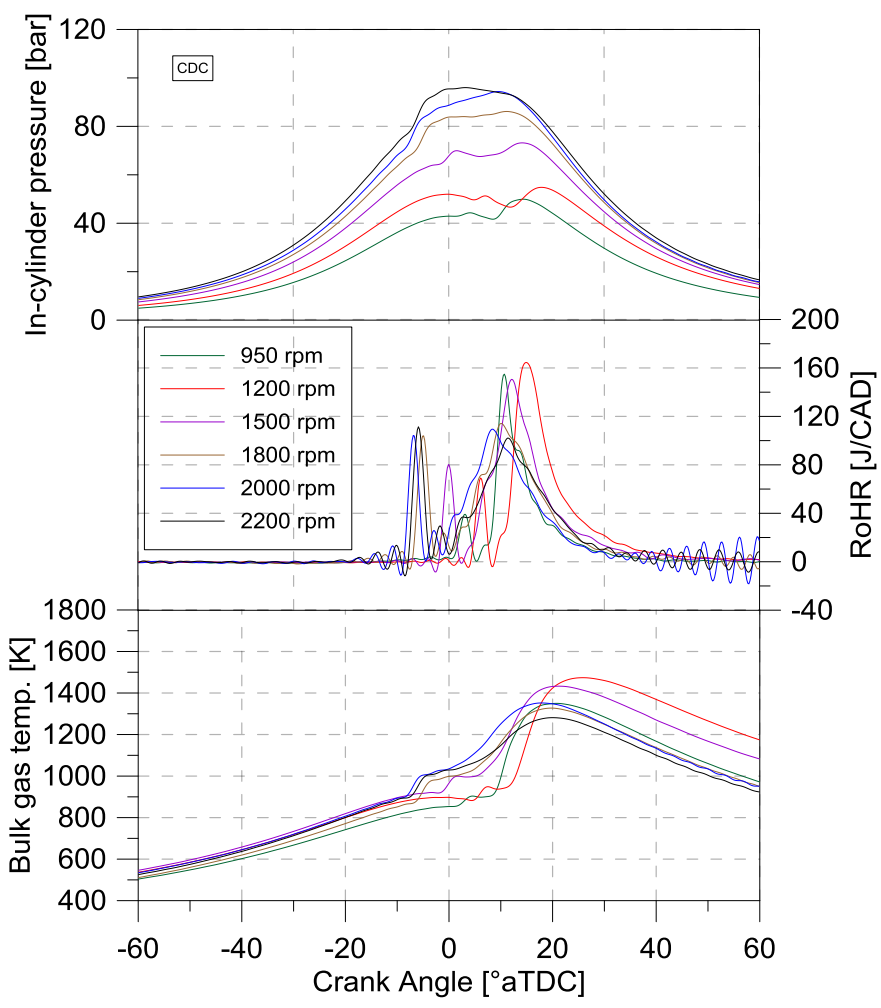

Figure 6. In-cylinder pressure, rate of heat release and bulk gas temperature for CDC.

Page 5 of 11
Figure 7 shows the mixing time (CA10-EoI), the CAD where the $90 \%$ of the fuel mass is burnt (CA90), the CAD where the $10 \%$ of the fuel mass is burnt (CA10), the combustion duration (CA90-CA10) and the bulk gas temperature for both operating modes. Additionally, gasoline fraction (GF) is also shown for RCCI mode. RCCI has a clearly premixing behavior due to the mixing time, which is almost 4 times greater than the $\mathrm{CDC}$ mode. The combustion duration increases in angle for the RCCI mode, but the duration in time remains quite constant (1500 rpm: $1.53 \mathrm{~ms}$ and $2200 \mathrm{rpm}: 1.36 \mathrm{~ms}$ ). On the other hand, CDC cases shows an increasing combustion duration in angle, but the duration of the combustion in time decreases with the engine speed. (1500 rpm: $2.73 \mathrm{~ms}$ and $2200 \mathrm{rpm}: 2.32 \mathrm{~ms}$ ).
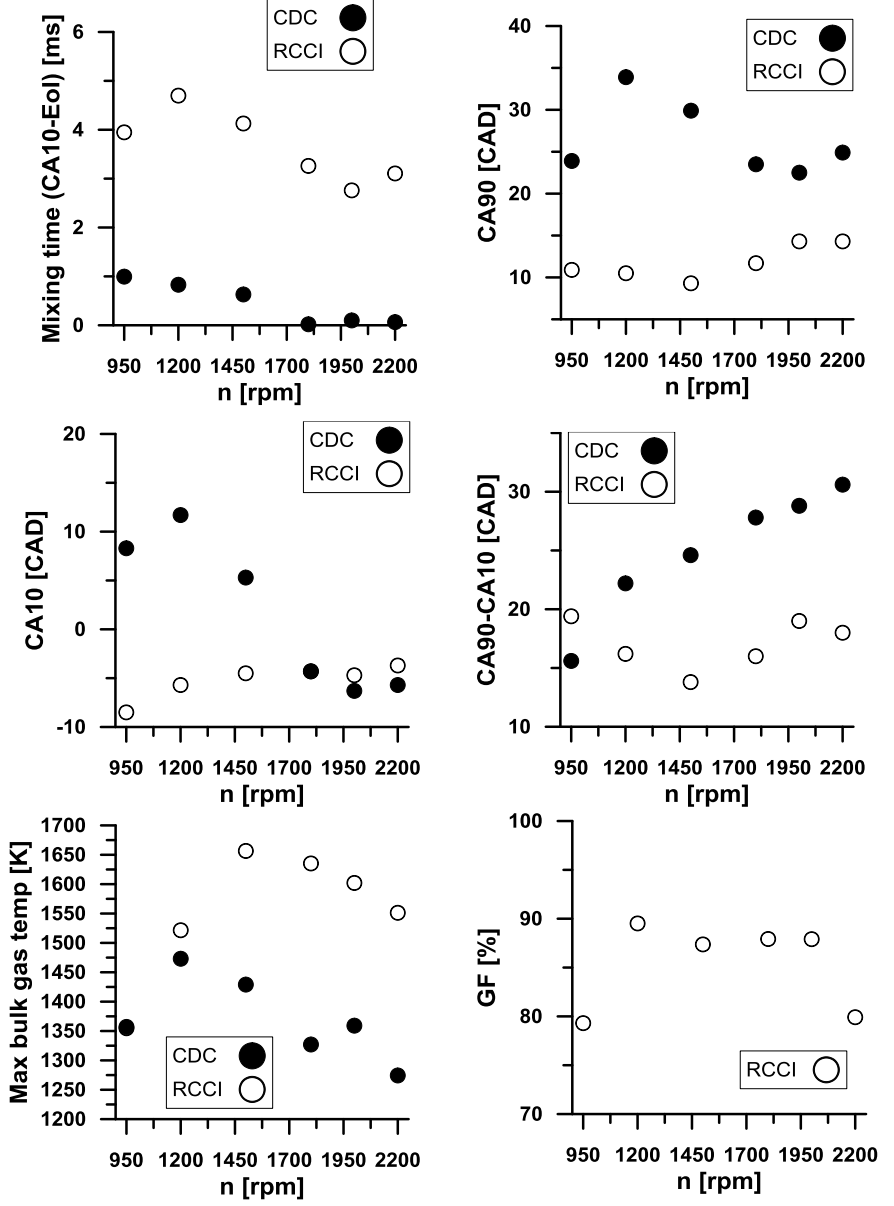

Figure 7. Mixing time, CA90, CA10, combustion duration (CA90-CA10) and bulk gas temperature for both modes and gasoline fraction (GF) for RCCI mode.

Figure 8 presents the maximum pressure rise rate (PRR) and the maximum in-cylinder pressure. The CDC pressure curves depicted in Figure 6 show that the in-cylinder pressure curves reach a higher peak values as the engine speed increases. Therefore, the values of IMEP presented in table 5 are maximum at the highest engine speed. RCCI cases have higher maximum pressure peaks than CDC at almost all engine speeds, only showing lower values at the two highest engine speeds. The pressure rise rate presents a similar trend, reaching the maximum value at $1500 \mathrm{rpm}$. As it can be figured out, the engine torque curve would present higher torque points for the mid-engine speed range, decreasing at lower and at higher engine speeds. However, CDC cases increase the IMEP at higher engine speeds. 

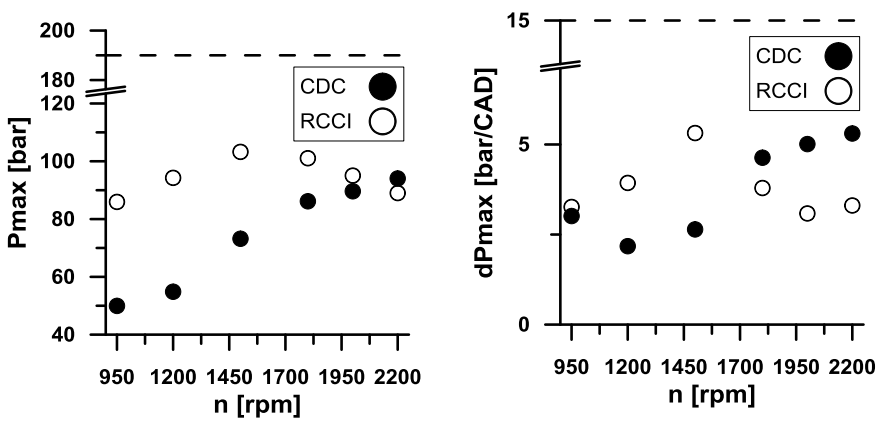

Figure 8. Maximum in-cylinder pressure and pressure rise rate peak for both modes.

Regarding NOx emissions presented in Figure 4, the values measured for RCCI mode are below EU VI limitation, while CDC mode presents emissions which exceed the standard emission regulation. Those ultra-low levels of NOx for RCCI mode suggest that are a consequence of thermal mechanisms. Despite of having higher maximum bulk gas temperatures than CDC, as it is observed in Figure 7, CDC mode promotes higher values of NOx. RCCI often presents higher values of bulk gas temperature than $\mathrm{CDC}$ at the same load, however CDC mode achieves higher peak local gas temperatures temperature in the rich reaction zone of the diesel spray. Hence, this difference between the peak bulk and the peak local temperatures might explain the differences of NOx emissions obtained between both combustion modes.

In Figure 4, $\mathrm{CO}$ and unburned $\mathrm{HC}$ emissions are presented. RCCI promotes higher levels of both emissions than CDC. Main differences between both operating modes are due to the gasoline injection at RCCI mode. In this sense, the gasoline fraction depicted in Figure 7 shows that more than $80 \%$ of the fuel mass injected is gasoline. The homogeneous mixture of the port fuel injected gasoline and air may produce high levels of gasoline trapped at the crevice volumes. Thus, during the combustion process, this gasoline might be not completely burnt producing high levels of $\mathrm{CO}$ and unburned $\mathrm{HC}$.

The evolution of the $\mathrm{CO}$ and unburned $\mathrm{HC}$ might be explained with the evolution of the bulk gas temperature. The higher the bulk peak gas temperature, the lower the emissions. The inverted U-shaped curve described by the bulk peak gas temperature produce a Ushaped curve for $\mathrm{CO}$ and $\mathrm{uHC}$ emissions as it is observed in Figure 7.

\section{Particle size and Number Emissions}

The following section summarizes the particle matter characterization for the engine points tested. The PSD measurements are depicted in figures 10,11 and 12 .

Figure 9 shows the total number of particles emitted from 5-250 nm. As it is seen, the particles number increases with the engine speed for both combustion modes, which was also observed in the smoke emissions trend up to $1800 \mathrm{rpm}$ (Figure 4). The figure also shows that the particles number is very similar for CDC and RCCI. This result differs from previous works [31-33], in which it is seen that CDC operation mode produces higher number of particles than RCCI. The different behavior found in the current investigation can be explained considering the stock calibration and hardware of the diesel engines used for comparison. In this sense, the majority of engines used in literature are calibrated to accomplish the EU IV type approval, while in the case of the present research the engine used is a currently under production EU VI heavy-duty engine. Thus, the stock diesel calibration relies on producing high levels of NOx, reduced later by means of a twin parallel SCR system, and low levels of smoke.

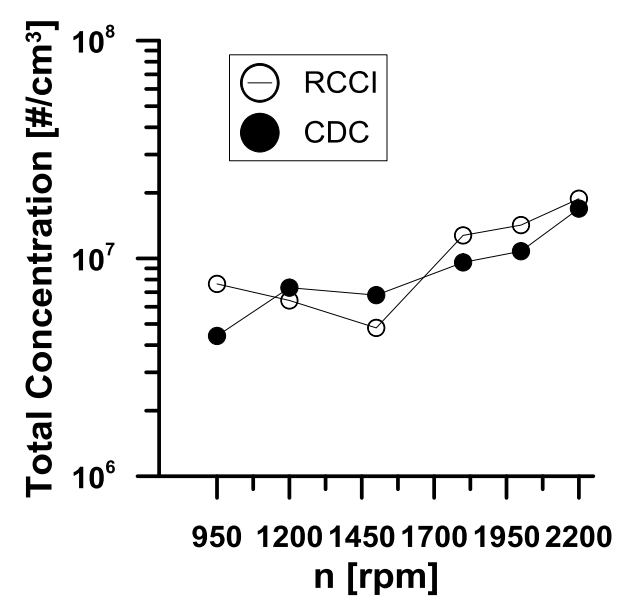

Figure 9. Total number of particles for RCCI and CDC mode.

Figures 10, 11 and 12 present the PSD at each engine speed for both operating modes. Tests have been performed at the same engine load $(25 \%)$, while the engine speed has been divided in six steps from 950 to $2200 \mathrm{rpm}$. Thus, six graphs compare the PSD of the RCCI mode versus the CDC mode. At first sight, RCCI curves at 950 and 2000 rpm seem to be noisy for larger particles, probably due to the low particle concentrations in the diluted exhaust. Something similar occurs at the CDC curve operated at $1500 \mathrm{rpm}$, where some noise affects the smoothness of the depicted curve.
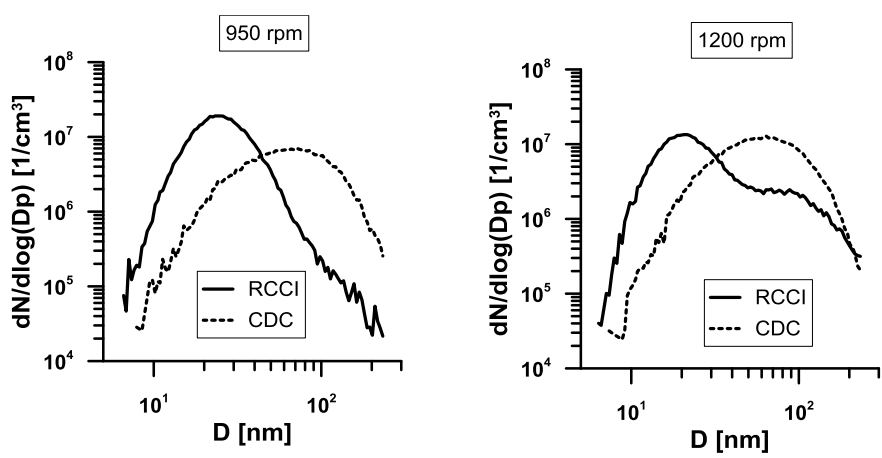

Figure 10. PSD at $950 \mathrm{rpm}$ and $1200 \mathrm{rpm}$.

Figure 10 shows the PSD obtained at 950 and $1200 \mathrm{rpm}$. CDC shows lower particle concentrations at low mobility diameters $(<30 \mathrm{~nm})$, being the difference higher at $950 \mathrm{rpm}$. On the other hand, CDC shows higher particle concentrations at high mobility diameter $(>30$ $\mathrm{nm})$. In any case, the differences in particles number are lower, suggesting that the total number of particles would be at the same order of magnitude. At $1200 \mathrm{rpm}$, the PSD curve present a bimodal shape. There is one main peak at $20 \mathrm{~nm}$ of diameter and a second peak at $80 \mathrm{~nm}$. This second peak presents lower number of particles that the particles measured at CDC mode. Moreover, CDC case presents a peak at $60 \mathrm{~nm}$ of mobility diameter, lower than for RCCI mode.

Page 6 of 11 

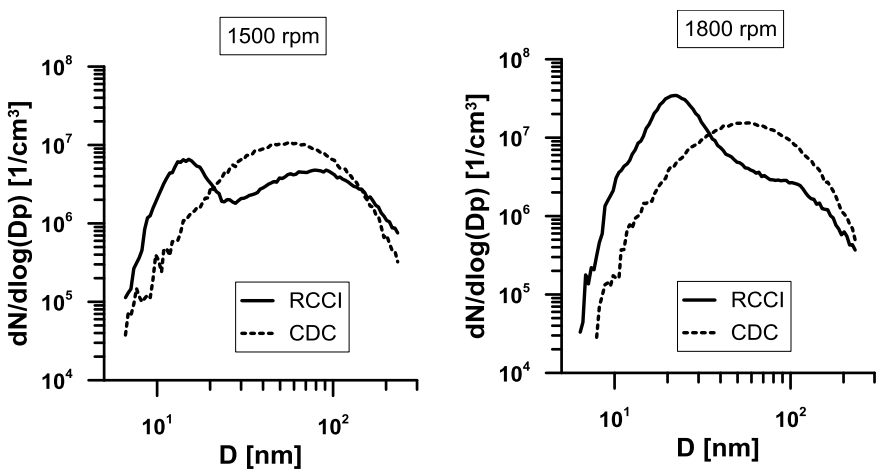

Figure 11. PSD at $1500 \mathrm{rpm}$ and $1800 \mathrm{rpm}$.

Figure 11 presents PSD curves for 1500 and $1800 \mathrm{rpm}$. The trend followed is very similar to the shapes presented in Figure 9. Main differences are found at RCCI mode, with a bimodal shaped curve at $1500 \mathrm{rpm}$. Operating under RCCI, the first peak observed at the PSD curve stands at $18 \mathrm{~nm}$, while the second peak is located at $90 \mathrm{~nm}$ of mobility diameter. These two peaks observed at the curve could be explained by the coagulation phenomenon. Particle coagulation is defined as a combination of growth by coalescence and agglomeration [36]. The ultra-low sized particles of soot added and the hydrocarbons particles might form the first peak, while the second peak might be formed by larger carbonaceous particles. In this sense, when high levels of small particles appear, new larger particles are formed by this phenomenon, increasing the number of large particles at the PSD curve. These particles usually come from volatile organics particles adhered to a carbonaceous nucleus, existing the possibility of being detected by the smokemeter (Figure 4). Hence, the higher value of FSN respect the other points. In addition, this phenomenon might be replicated at $1200 \mathrm{rpm}$ and 1800 rpm with lower magnitude of the second peak due to the smoke measurements presented in Figure 4 and the PSD curves showed in Figures 10 and 11.

PSD curves for CDC operation shows the same curve than that observed at $1200 \mathrm{rpm}$. In this sense, the total number of particles seems to be very similar, with a peak located at the same mobility diameter of $60 \mathrm{~nm}$.
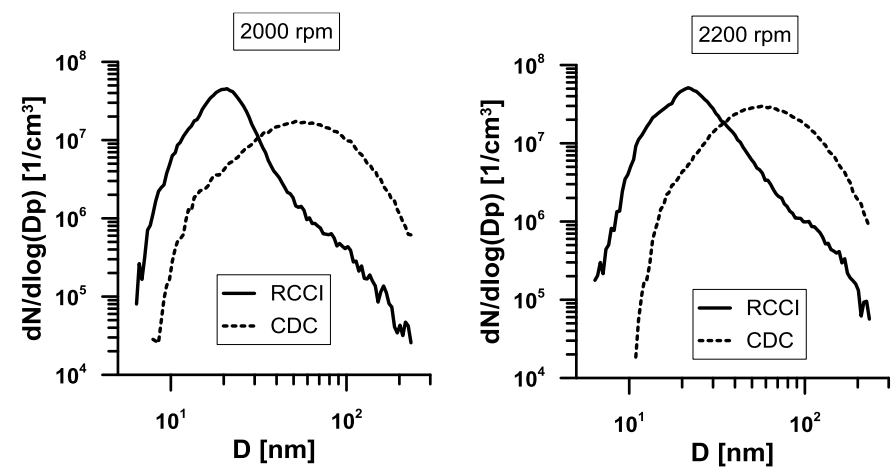

Figure 12. PSD at $2000 \mathrm{rpm}$ and $2200 \mathrm{rpm}$.

Figure 12 presents the PSD curves for 2000 and $2200 \mathrm{rpm}$. Both RCCI PSD curves show big differences with the previous RCCI PSD curves for $1500 \mathrm{rpm}$ and $1800 \mathrm{rpm}$, and also differ from those of CDC. The most relevant difference is that the second peak has disappeared. In this sense, only one peak is observed in both curves at $20 \mathrm{~nm}$ of mobility diameter in both engine speeds presented in the Page 7 of 11 figure. Therefore, it is worthy to note that the phenomenon of coagulation observed at 1500 and $1800 \mathrm{rpm}$ cases in not observed at these high engine speeds. Thus, low sized particles dominate the PSD at high engine speeds under RCCI.

PSD curves for CDC operation shows again the same trend that it has been observed at the other engine speeds. In this sense, the total number of particles for the PSD peak seems to be slightly increased and the diameter where the PSD peak appears is kept constant around $60 \mathrm{~nm}$.

From the nature of the particles standpoint, PSD analysis provides information about the mobility diameter of the particles and the number of particles corresponding with each diameter measured. Additionally, a nucleation or accumulation mode classification has been performed in order to identify the nature of the particles and the portion of representation for each mode type respect the total number of particles.

Figure 13 presents the particle classification in nucleation or accumulation mode, the total number of particles and the smoke emissions in FSN. Smoke emissions has been added to the graph in order to improve the understanding of the classification and observe the correlation existing between the smoke emissions and the accumulation mode particles emission
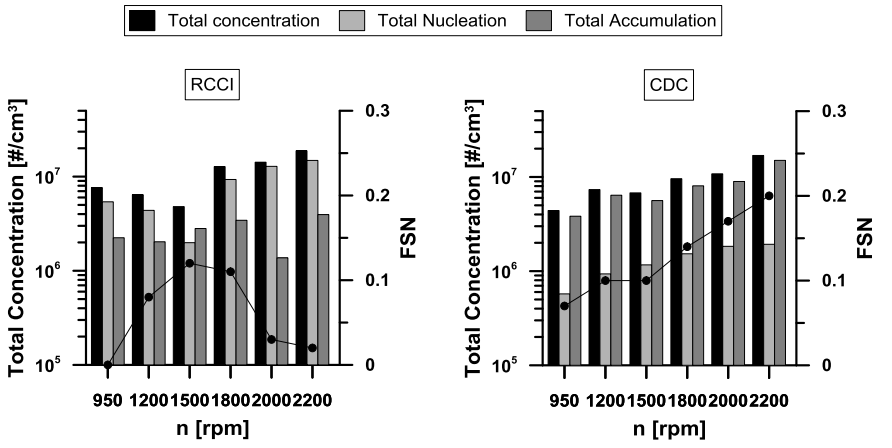

Figure 13. Classification of the mode of the particles for both combustion modes.

CDC PSD curves presented in Figures 10, 11 and 12, show the PSD peaks at a mobility diameter around $60 \mathrm{~nm}$. Therefore, large sized particle domination of the PSD indicates that the majority of the particles have a carbonaceous origin. In this sense, the cutoff diameter used to limit as the nucleation mode as the accumulation mode has been $30 \mathrm{~nm}$. This cutoff diameter ensures that the nature of the particles is kept in the correct particle counter. Thus, CDC classification is presented on the right graph. It is observed that the particle emission measured is dominated by large sized particles, which are provided by the soot produced during the combustion. Smoke emissions are also depicted in the figure and is directly related with the accumulation mode particles. As the smoke emissions increase with the engine speed, the number of accumulation particle increases as well, whereas the number of nucleation mode particles remains almost constant along the engine speeds tested.

RCCI graph shows the classification of the total number of particles and the corresponding nucleation mode and accumulation mode particles. Considering the explanation given at the previous paragraph, the cutoff diameter selected has been $30 \mathrm{~nm}$. As it is depicted in Figure 13, the smoke emissions measurement and the total number of particles do not follow the same trend. Indeed, the 
smoke measurement presents the maximum value at $1500 \mathrm{rpm}$, and the total number of particles presents a minimum point. Therefore, it is possible to assume that RCCI is dominated by lower sized particles for all engine speeds. Nucleation mode particles are usually formed by volatile organic and sulfur compounds that are produced during the exhaust dilution. So that, smoke measurement is not able to detect this small particles where they are captured in the paper sample.

Comparing the total number of particles emitted by both modes, except at high engine speed that offers similar results, the number of particles is higher for RCCI than for CDC mode.

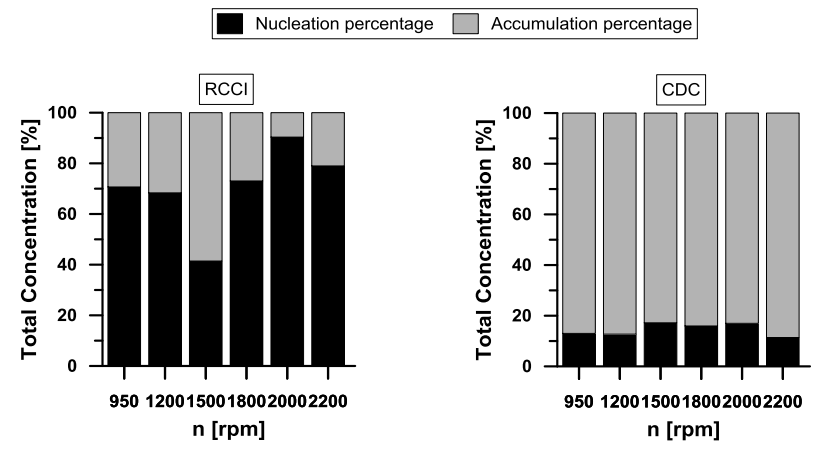

Figure 14. Concentration of nucleation and accumulation mode particles respect the total concentration of particles.

Figure 14 shows the percentage of nucleation and accumulation mode particles respect the total concentration of particles obtained. Big differences are found between the RCCI mode and the CDC mode, confirming that RCCI is dominated by the nucleation mode particles and CDC is dominated by accumulation mode particles.

Both combustion modes present a trend between the smokemeter results and the accumulation percentage depicted in the Figures 13 and 14. As the smoke measurements increase, the percentage of accumulation mode particles also increase. This trend might be explained by the diameter of the particles. At CDC mode, it is wellknown the different correlations to convert the smoke measurements in soot mass as well as the nature and morphology of the particle. However, the nature of the particles and the correlations for RCCI are not accurately defined even more these big particles come from a coagulation phenomenon process.

\section{Conclusions}

The present investigation has been focused on the particle size distribution (PSD) comparison between RCCI and CDC mode. This investigation has been carried out in a medium-duty EURO VI diesel engine adapted to run with two different fuels at the same time. The points tested were performed at $25 \%$ engine load and six steps of engine speed from 950 to $2200 \mathrm{rpm}$.

From the gaseous emissions standpoint, the most relevant conclusions from the study are:

- Ultra-low NOx emissions obtained for RCCI. In spite of having the RCCI concept higher bulk gas temperatures than $\mathrm{CDC}$, local peak gas temperatures are lower. Hence RCCI promotes lower NOx values.

- Unacceptable levels of CO and uHC have been obtained at all engine speeds. These levels should be caused by the crevices volume, which difficult the gasoline burning during the combustion process.

From the PSD analysis standpoint, the most relevant conclusions from the study are:

- Small-sized particles dominate the RCCI particle emissions. PSD curves present the peaks at a mobility diameter of around $20 \mathrm{~nm}$ in all the engine speeds tested.

- $\quad$ PSD analysis carried out for a medium-duty engine shows a dependency between the total number of particles and the engine speed for both combustion modes. Despite of having lower smoke values, RCCI mode promotes slightly higher number of particles at high engine speeds. These small particles might be caused by the gasoline ( $\mathrm{CO}$ and uHC emissions) at RCCI mode and the smoke at CDC mode.

- FSN measurements have not a direct correlation with the total number of particles for RCCI concept. As literature describes, RCCI particles present a carbonaceous nucleus nature in which semi-volatile organics are adhered and thereby, the smallest particles cannot be detected by the smokemeter.

- $\quad$ FSN measurements for $1200 \mathrm{rpm}, 1500 \mathrm{rpm}$ and $1800 \mathrm{rpm}$ and their respective PSD curves suggest that the particles derived from a coagulation phenomenon might be detected by the smokemeter. This finding is coherent with the literature, which shows that RCCI particles present a nucleus of carbon and brown colored particles that might be detected by the smokemeter.

\section{References}

1. Akagawa H, Miyamoto T, Harada A, Sasaki S, Shimazaki N, Hashizume T, Tsujimura K. "Approaches to Solve Problems of the Premixed Lean Diesel Combustion," SAE Technical Paper 199-01-0183, 1999.

2. Yanagihara H, Sato Y, Minuta J. "A simultaneous reduction in NOx and soot in diesel engines under a new combustion system (Uniform Bulky Combustion System e UNIBUS)," In: 17th International Vienna motor symposium; 1996.-14-303, 1996.

3. Wu HW, Wang RH, Ou DJ, Chen YC, Chen TY. "Reduction of smoke and nitrogen oxides of a partial HCCI engine using premixed gasoline and ethanol with air," Appl Energy 2011-9080, 2011.

4. Benajes J, Molina S, García A, Monsalve-Serrano J, Durrett R. "Performance and engine-out emissions evaluation of the double injection strategy applied to the gasoline partially premixed compression ignition spark assisted combustion concept". Applied Energy, Volume 134, 2014, Pages 90-101.

5. Benajes J, Molina S, García A, Monsalve-Serrano J, Durrett R. "Conceptual model description of the double injection strategy applied to the gasoline partially premixed compression ignition combustion concept with spark assistance". Applied Energy, Volume 129, 2014, Pages 1-9.

6. Yang B, Yao M, Cheng WK, Li Y, Zheng Z, Li S. "Experimental and numerical study on different dual-fuel combustion modes fueled with gasoline and diesel," Apl Energy 2014-33-113, 2014.

7. Najafabadi MI, Aziz NA. "Homogeneous charge compression ignition combustion: challenges and proposed solutions," J. Combustion, 2013-783, 2013. 
8. Lu X, Han D, Huang Z. "Fuel design and management for the control of advanced compression-ignition combustion modes," Prog Energy Combust Sci 2011-37-741, 2011.

9. Bessonette PW, Schleyer CH, Duffy KP, Hardy WL, Liechty MP. "Effects of fuel property changes on heavy-duty HCCI combustion," SAE paper 2007-01-0191; 2007.

10. Manente V, Tunestal P, Johansson B et al." Effects of Ethanol and Different Type of Gasoline Fuels on Partially Premixed Combustion from Low to High Load," SAE Technical Paper 2010-01-0871, 2010.

11. Singh AP, Agarwal AK. "Combustion characteristics of diesel HCCI engine: an experimental investigation using external mixture formation technique," Appl Energy 2012-25-99:116, 2012.

12. Bessonette P, Schleyer C, Duffy K, Hardy W., Liechty M. "Effects of Fuel Property Changes on Heavy-Duty HCCI Combustion". SAE Technical Paper 2007-01-0191, 2007.

13. Kalghatgi GT. "Auto-ignition quality of practical fuels and implications for fuel requirements of future SI and HCCI engines," SAE paper 2005-01-0239, 2005.

14. Kalghatgi G, Risberg P, Angstrom H. "Advantages of fuels with high resistance to autoignition in late-injection, low-temperature, compression ignition combustion," SAE Trans 2006-34-623, 2006.

15. Borgqvist P, Tunestal P, Johansson B. "Gasoline Partially Premixed Combustion in a Light Duty Engine at Low Load and Idle Operation Conditions," SAE Technical Paper, 2012-010687, 2012.

16. Lewander M, Ekholm K, Johansson B, Tunestal P Milovanovic Nebojsa, KN, Harcombe T, Bergstrand P. "Investigation of the Combustion Characteristics with Focus on Partially Premixed Combustion in a Heavy duty Engine," SAE Int. J. Fuels Lubr., 2008-06-1063, 2008.

17. Park H, Youn IM, Lim Y, Lee CS. "Influence of the mixture of gasoline and diesel fuels on droplet atomization, combustion and exhaust emission characteristics in compression ignition engine," Fuel Processing Technology 2013-106-392, 2013.

18. Inagaki K, Fuyuto T, Nishikawa K, Nakakita K, Sakata I. "DualFuel PCI Combustion Controlled by In-Cylinder Stratification of Ignitability," SAE Technical Paper 2006-01-0028, 2006.

19. Kokjohn SL, Hanson M, Splitter D, Reitz RD. "Experimental Moodeling of Dual-Fuel HCCI and PCCI Combustion Using InCylinder Fuel Blending," SAE Technical Paper 2009-01-2647, 2009.

20. Benajes J, Molina S, García A, Monsalve-Serrano J. "Effects of Direct injection timing and Blending Ratio on RCCI combustion with different Low Reactivity Fuels". Energy Conversion and Management, Volume 99, 2015, Pages 193-209.

21. Benajes J, Molina S, García A, Monsalve-Serrano J. "Effects of low reactivity fuel characteristics and blending ratio on low load RCCI (reactivity controlled compression ignition) performance and emissions in a heavy-duty diesel engine". Energy, Volume 90, 2015, Pages 1261-1271.

22. Benajes J, García A, Pastor J.M, Monsalve-Serrano J. "Effects of piston bowl geometry on Reactivity Controlled Compression Ignition heat transfer and combustion losses at different engine loads". Energy, Volume 98, 2016, Pages 64-77.

23. Benajes J, Pastor José V, García A, Monsalve-Serrano J. “An experimental investigation on the Influence of piston bowl geometry on RCCI performance and emissions in a heavy-duty engine". Energy Conversion and Management, Volume 103, 2015, Pages 1019-1030.

24. Desantes JM, Benajes J, García A, Monsalve-Serrano J. "The role of the in-cylinder gas temperature and oxygen concentration over low load reactivity controlled compression ignition

Page 9 of 11 combustion efficiency”. Energy, Volume 78, 2014, Pages 854868.

25. Benajes J, Pastor J.V, García A, Monsalve-Serrano J. “The potential of RCCI concept to meet EURO VI NOx limitation and ultra-low soot emissions in a heavy-duty engine over the whole engine map". Fuel, Volume 159, 2015, Pages 952-961.

26. Benajes J, García A, Monsalve-Serrano J, Balloul I, Pradel G. "An assessment of the dual-mode reactivity controlled compression ignition/conventional diesel combustion capabilities in a EURO VI medium-duty diesel engine fueled with an intermediate ethanol-gasoline blend and biodiesel". Energy Conversion and Management, Volume 123, 2016, Pages 381-391.

27. Benajes J, Pastor JV, García A, Boronat V. "A RCCI operational limits assessment in a medium duty compression ignition engine using an adapted compression ratio," Energy Conversion and Management, 2016-126-497, 2016.

28. Kittelson D. "Engine and Nanoparticles: a Review," Journal of Aerosol Science, 1998-29-575, 1998.

29. Shi J, Harrison R, Brear F. "Particle size distribution from a modern heavy duty diesel engine," The Science of the Total Environment, 1999-235-305, 1999.

30. Storey J, Curran S, Lewis S, Barone T, Dempsey T, MosesDeBusk M, Hanson M, Prikhodko V, Northrop W. "Evolution and current understanding of physicochemical characterization of particulate matter from reactivity controlled compression ignition combustion on a multi cylinder light-duty engine," International Journal of Engine Research, 2016.

31. Kolodziej C, Wissink M, Splitter D, Hanson R. "Particle Size and Number Emissions from RCCI with Direct Injections of Two Fuels," SAE Technical Paper, 2013.

32. Zhang Y, Ghandhi J, Rothamer D. "Comparison of Particulate Size Distributions from Advanced and Conventional Combustion - Part I: CDC, HCCI, and RCCI," SAE Int. J. Engines, 2014.

33. Prikhodko V, Curran S, Barone T, Lewis S. "Emission Characteristics of a Diesel Engine Operating with In-Cylinder Gasoline and Diesel Fuel Blending," SAE Int. J. Fuels Lubr., 2010-946, 2010

34. Northrop W, Bohac S, Chin J, Assanis D. "Comparison of filter smoke number and elemental carbon mass from partially premixed low temperature combustion in a direct-injection diesel engine," J Eng Gas Turb Power 2011-133, 2011.

35. Benajes J, García A, Monsalve-Serrano J, Boronat V. "DualFuel Combustion for Future Clean and Efficient Compression Ignition Engines," Applied Sciences 2017-7-36, 2017.

36. Harris SJ, Maricq MM. "Signature size distributions for diesel and gasoline engine exhaust particulate matter," Journal of Aerosol Science, 2001-32-749, 2001.

\section{Contact Information}

Dr. Antonio García (angarma8@ mot.upv.es)

Phone: +34 963879659

Fax: +34963877659

\section{Acknowledgments}

This investigation has been funded by VOLVO Group Trucks Technology. The authors also acknowledge the Spanish economy and competitiveness ministry for partially supporting this research 
(HiReCo TRA2014-58870-R). The predoctoral contract of the author V. Boronat (FPI-S2-2017-2882) is granted by the Programa de Apoyo para la Investigación y Desarrollo (PAID) of the Universitat Politècnica de València. The author J. Monsalve-Serrano acknowledges the financial support from the Universitat Politècnica de València under the grant "Ayudas Para la Contratación de Doctores para el Acceso al Sistema Español de Ciencia, Tecnología e Innovación".

\section{Abbreviations}

AIM

aTDC

CAD

CA10

CA50

CA90

CDC

CI

CO

CPC

CR

DI

DM

DMA

DMDF

ECU

EGR

EOI

EU

EVO

GF

FSN
Aerosol Instrument Manager

After Top Dead Center

Crank Angle Degree

Crank angle at $10 \%$ mass

fraction burned

Crank angle at 50\% mass

fraction burned

Crank angle at $90 \%$ mass

fraction burned

Conventional Diesel

Combustion

Compression Ignition

Carbon Monoxide

Condensation Particle

Counter

Compression Ratio

Direct Injection

Dual Mode

Differential Mobility

Analyzer

Dual Mode Dual Fuel

Engine Control Unit

Exhaust Gas Recirculation

End of Injection

European Union

Exhaust Valve Open

Gasoline Fraction

Filter Smoke Number
uHC

Unburned Hydro Carbons

HCCI

Homogeneous Charge

Compression Ignition

IMEP

ISFC

IVC

IVO

LHV

LTC

MCE

MON

MPRR

OEM

ON

PFI

PPC

PRR

PSD

RCCI

RoHR

RON

SC

SCE

SMPS

SOC

SOI

DC
Indicated Mean Effective Pressure

Indicated Specific Fuel

Consumption

Intake Valve Close

Intake Valve Open

Lower Heating Value

Low Temperature

Combustion

Multi Cylinder Engine

Motor Octane Number

Maximum Pressure Rise

Rate

Original Equipment

Manufacturer

Octane Number

Port Fuel Injection

Partially Premixed Charge

Pressure Rise Rate

Particle Size Distribution

Reactivity Controlled

Compression Ignition

Rate of Heat Release

Research Octane Number

Screw Compressor

Single Cylinder Engine

Scanning Mobility Particle

Sizer

Start of Combustion

Start of Injection

Top Dead Center

Page 10 of 11 
Page 11 of 11

$10 / 19 / 2016$ 